\title{
LA REDUNDANCIA LINGÜÍSTICA Y LAS NORMAS ESPECIALES. ALGUNOS USOS DEL PRINCIPIO LEX SPECIALIS *
}

\author{
Silvia Zorzetto \\ Università degli studi di Milano
}

RESUMEN. Este artículo contiene un análisis del principio lex specialis. En particular, es una investigación preliminar acerca de su uso en los casos en que las normas especiales y generales son compatibles en lugar de encontrarse en conflicto. El punto de partida es que las normas especiales y las normas generales son, por definición, normas redundantes sobre la base de la lógica y el lenguaje, en cuanto todas las especies se encuentran lógicamente incluidas en el género al que pertenecen. Pero, además, cuando las normas especiales y las normas generales son compatibles y, por lo tanto, pueden prima facie concurrir y ser aplicadas en conjunto, puede darse también una redundancia normativa. Así, el análisis se divide en tres partes. En la primera parte, el tema principal es la especialidad del derecho y la relación de derogación entre normas especiales y generales. En la segunda parte se presentan de manera bastante esquemática las redundancias lingüísticas en los lenguajes naturales. En la tercera parte se introducen y discuten algunos ejemplos de la particular redundancia de las normas, con la finalidad de explicar las funciones pragmáticas y discursivas de las redundancias en el derecho.

Palabras claves: razonamiento jurídico, lenguaje jurídico, normas jurídicas, principio lex specialis, redundancias.

\section{Linguistic redundances and special rules. Some uses of the lex specialis principle}

ABSTRACT. This essay is an analysis of the lex specialis principle: in particular, it is an initial inquiry into its uses when special and general rules are compatible, rather than conflicting. The starting point of the analysis is that special and general rules are, by definition, redundant rules on the grounds of logic and language, insofar as all species are logically included in their genre. But, in addition, when special and general rules are compatible and, hence, shall prima facie concur and be applied together, there might be a normative redundancy too. Thus, the analysis is divided in three parts. In the first part, the main topics are the speciality of law and the derogation between special and general rules. In the second part it is portrayed a rough sketch of linguistic redundancies in natural languages. In the third part some examples of special redundant rules are illustrated and discussed in order to explain the pragmatic and discursive functions of redundancies in law. dances.

Keywords: legal reasoning, legal language, legal rules, lex specialis principle, redun-

\footnotetext{
* Fecha de recepción: 1 de julio de 2013. Fecha de aceptación: 6 de septiembre de 2013.
} 


\section{INTRODUCCIÓN}

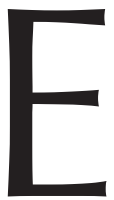

n este trabajo me referiré al tema de la lex specialis, analizando, en particular, el caso de las normas especiales compatibles con las normas más generales. Generalmente se presta escasa atención a este caso. Cuando se habla de lex specialis se piensa, en efecto, sobre todo en el adagio «lex specialis derogat legi generali» como criterio de solución de las antinomias jurídicas, en particular, a la antinomia llamada «parcial-total», puesto que se asume que la norma especial y la norma general están en conflicto. En lo que sigue, me referiré sólo brevemente a este último caso y, en cambio, me ocuparé sobre todo de la derogación entre normas especiales y generales compatibles, y de las redundancias lingüísticas que generan la coexistencia de normas especiales y generales.

Mi trabajo se divide en tres partes.

En la primera parte explicaré brevemente: (i) en que consiste la especialidad de las normas, o sea, qué quiere decir que una norma es especial y bajo cuáles condiciones lo es; (ii) en qué consiste la derogación por norma especial, o sea, qué quiere decir que una norma especial deroga a otra norma (más general), y si y bajo qué condiciones eso sucede. La visión minimalista del principio de lex specialis que propondré tiene el objetivo de explicar el uso que de tal principio hacen los jueces y los juristas, como también los teóricos. Por ello, tendrá en cuenta el uso que se hace del principio en el razonamiento jurídico relativo, no sólo a los conflictos entre normas especiales y generales, sino también a su concurso (o acumulación) ya su integración en una norma más comprensiva. Considerando estos diferentes usos, el principio de la lex specialis se puede reconstruir como una meta-regla sobre la aplicación externa que establece una jerarquía material entre las normas previamente identificadas como lógicamente ordenadas en base a una relación de especialidad. Es decir, como una meta-regla que dispone el uso exclusivo de la norma relevante (más) especial como base de la justificación interna del caso ${ }^{1}$.

Una vez hecho eso, en la segunda parte haré referencia a algunos estudios de lingüística sobre el fenómeno de la redundancia en los lenguajes naturales ${ }^{2}$. Según mi parecer, estos estudios representan un instrumento metodológico útil para analizar la dimensión lingüística de las redundancias que generan las normas especiales y generales. Dada la naturaleza de la relación de especialidad, la redundancia entre una norma especial y una norma general tiene una naturaleza semántico-pragmática además de lógico-sintáctica. En el sentido de que se ve influenciada por las características semióticas de los lenguajes naturales y del lenguaje jurídico, sobre todo a nivel pragmático.

\footnotetext{
1 Sobre los criterios jerárquicos y sobre las nociones de jerarquía material y de aplicabilidad interna y externa que uso aquí vid. FERRER y RODRíGUeZ, 2011: 135 y ss.

2 No haré referencia, por lo tanto, al amplio conjunto de estudios sobre la redundancia de la denominada teoría de la información. Tampoco me referiré a los enfoques lógico-formales o a los estudios cuantitativos que conciben la redundancia como previsibilidad de la repetición de determinados elementos de un código y se ocupan de medirla. La decisión de privilegiar los estudios de lingüística, y en particular los análisis relativos a los lenguajes naturales, deriva del hecho que los ordenamientos jurídicos vigentes usan los lenguajes naturales para expresar las normas y, además, del hecho que la abstracción conceptual y la comprensión de los significados de los símbolos son habilidades que, también en ámbito jurídico, se fundan sobre la más fundamental capacidad de usar y comprender los lenguajes naturales, comenzando por la lengua madre.
} 
Esto vale, ya sea para los derechos fundados en lo escrito, ya sea para los derechos y los fenómenos jurídicos no fundados en lo escrito. En este análisis, de todos modos, haré referencia directamente a los primeros y tomaré los ejemplos de textos escritos.

En la tercera parte intentaré, a continuación, introducir en el contexto jurídico los estudios sobre las redundancias en los lenguajes naturales y examinaré algunos casos paradigmáticos de normas especiales y generales (compatibles) redundantes. La hipótesis de investigación que quisiera someter a discusión es que, con respecto a las normas especiales y generales compatibles, la aplicación o no aplicación del principio de lex specialis por parte de juristas y jueces depende también, aunque no solo, del tipo de redundancia. La intuición inicial es que investigar, sobre el plano lingüístico, las redundancias entre las normas especiales y generales compatibles, es un primer paso para entender por qué algunas normas son consideradas derogatorias y concurrentes, mientras otras, en cambio, son consideradas no derogatorias y resultan combinadas con las normas más generales para formar una norma más comprensiva.

\section{LA ESPECIALIDAD}

¿Qué se quiere decir cuando se afirma que una norma es «especial»? ¿Bajo qué condiciones una norma es especial? Para responder a estas preguntas conviene comenzar a partir de dos ejemplos.

La probibición de andar en bicicleta por los senderos de los parques de la ciudad especifica (es especial con relación a) la más general prohibición de ingreso de vebículos en las zonas verdes de la ciudad, teniendo en cuenta que cada bicicleta es un vehículo y que para andar por los senderos de los parques es necesario ingresar en una zona verde. En este ejemplo, la relación de especialidad entre las normas se apoya sobre cuatro elementos conceptuales: 1) las bicicletas están concebidas como especie del género vehículo (se reconstruye el concepto de bicicleta como incluido en el concepto de vehículo);2) los parques de la ciudad entran en el género más amplio constituido por las zonas verdes de la ciudad (el concepto de zona verde de la ciudad incluye el de parque de ciudad); 3) los senderos del parque forman parte del parque como zona verde ;3) el andar dentro de un espacio presupone ingresar en él, tanto que las calles de un parque o de una zona verde se recorren, donde el «recorrer» indica «atravesar un espacio o lugar en toda su extensión o longitud».

Las normas de los tratados internacionales son habitualmente consideradas, por los juristas, y no sólo, como normas especiales respecto de las normas de derecho internacional consuetudinario, las cuales son, a su vez, consideradas generales respecto a las primeras. La relación de especialidad entre los dos conjuntos de normas se basa sobre una asunción implícita, relativa al origen de las normas en cuestión. La asunción de la

\footnotetext{
3 Vale señalar que esta asunción no es tan obvia como podría parecer. En muchas circunstancias los senderos —y, más en general, los espacios transitables dentro de las zonas verdes — no son considerados ellos mismos zona verde y, en consecuencia, se les aplican reglas diferentes. En los parques y jardines de la ciudad es frecuente, por ejemplo, que esté prohibido circular con cualquier vehículo sobre canteros y sobre el césped (para no arruinarlo), pero que esté permitido transitar sobre las callecitas en bicicleta, con patines, en skateboard, con autitos de juguete, etcétera.
} 
cual se parte es que las normas de los tratados internacionales derivan del acuerdo de determinados miembros de la comunidad internacional (las partes del tratado) y, por lo tanto, se originan en una determinada forma de interacción (el acuerdo), entre agentes identificados (algunos miembros de la comunidad). En cambio, las normas consuetudinarias internacionales derivan de la interacción entre miembros de la comunidad, sin distinciones, siendo indiferente quién y cómo interactúa. Nótese que también aquí, como en el ejemplo anterior, existe un orden lógico entre los conceptos, a saber, la interacción entre los miembros de la comunidad internacional incluye, como especie, el acuerdo entre algunos de sus miembros ${ }^{4}$.

Estos ejemplos muestran que la especialidad jurídica es una cuestión lógico-conceptual, que depende de cómo se conciban las normas, e inherente a sus elementos conceptuales. Asimismo, muestra que la especialidad jurídica exige identificar previamente un género y una o más diferencias específicas relevantes.

A menudo, los teóricos tienden a trazar una diferencia esencial entre los casos de especialidad del primer y segundo tipo. Y aún más, tienden a considerar genuinos casos de especialidad solo los casos del primer tipo; donde la especialidad se evidencia comparando lo que cada norma prescribe, en particular, comparando las situaciones a las que cada norma se refiere (el andar en bicicleta por los senderos del parque de la ciudad - el ingreso de vehículos en las zonas verdes de la ciudad). Al respecto, se habla también de especialidad relativa a los casos, y el ejemplo es una muestra típica e intuitiva de este tipo de especialidad, porque en el ejemplo las modalidades deónticas son idénticas («prohibido», «prohibido») y, por lo tanto, son un elemento común a las dos normas.

Sin embargo, también el segundo ejemplo es un caso de especialidad. Como fundamento de la especialidad existe, en este caso, una verdadera y propia teoría de los géneros y de las especies, que concierne, como decía, al origen de las normas internacionales convencionales y consuetudinarias. A menudo se tiende a afrontar el segundo ejemplo como una cuestión de jerarquía entre las fuentes, no de especialidad. Pero una perspectiva no excluye la otra. Al contrario, puesto que las normas convencionales se fundan sobre el principio pacta sunt servanda, que es una norma internacional consuetudinaria, las normas de los tratados internacionales son especificación de ese principio; normas especiales, respecto del principio general, en virtud de su origen.

Por tanto, para que una norma sea especial respecto de otra norma, es necesario identificar previamente en cada norma, al menos un elemento que se encuentren, uno respecto del otro, en relación de especie a género y viceversa. Tomando prestada una noción de la lógica, podemos llamar a estos conceptos «términos determinantes», porque de ellos depende la calificación de las normas como especiales y generales. En

${ }^{4}$ Respondo anticipadamente a una posible objeción. La especialidad entre las normas convencionales y consuetudinarias internacionales no se basa sobre razones extensionales, relativas al campo de aplicación espacial de tales normas. Una norma convencional acordada hipotéticamente por todos los miembros de la comunidad internacional (que tendría en consecuencia máxima extensión espacial) es considerada de todos modos especial respecto de las normas consuetudinarias internacionales (en cuanto fundada sobre el acuerdo entre determinadas partes). A su vez, una norma consuetudinaria regional, o sea, relativa sólo a algunos territorios del Planeta —y que por lo tanto tiene extensión menor que la norma convencional recién hipotetizada — es de todos modos considerada una norma general, siempre en virtud de su origen/modalidad de formación. 
consecuencia, la especialidad/generalidad de las normas es, por así decir, una propiedad derivada, basada sobre una relación más fundamental entre sus elementos conceptuales. El ser general y el ser especial son una propiedad de las normas, lógicamente correlacionadas y opuestas, que indican y presuponen una relación de genus ad speciem entre algunos elementos conceptuales a los cuales los intérpretes, en base a previas asunciones de relevancia, dan un rol de genus y de species.

Como muestran también los ejemplos, la dimensión lógica y, más precisamente, la dimensión de sintaxis lógica de la especialidad jurídica consiste en el hecho que, los términos determinantes, para poder ser ordenados de género a especie, deben ser reconstruidos como clases lógicas (o sea, deben ser pensados como perfectamente precisos o exactamente definidos) ordenadas según la relación de inclusión lógica ${ }^{5}$. Esta relación, formalizada por la lógica, es una modalidad fundamental del pensamiento humano en todo ámbito. Así, para la zoología, todos los mamíferos son animales, por lo que si un puerco espín es un mamífero ha de ser también un animal; en la geometría euclidiana, todos los cuadrados con rectángulos, por lo que algo puede tener forma cuadrada únicamente bajo condición que sea (incluso antes) rectangular. Por lo que no es sorprendente que lo sea también en ámbito jurídico. Sin embargo, en cada ámbito, como la lógica y la matemática, los lenguajes naturales y el derecho, la relación de género a especie como inclusión lógica tiene un fundamento semántico, en virtud de lo cual, la especialidad (jurídica) es ciertamente una cuestión lógica, pero no solo de sintaxis lógica. Establecer cuáles características de las normas son relevantes y asumen el rol de género y diferencia específica no es una cuestión lógica, sino fruto de elecciones conceptuales ${ }^{6} y$ de justicia. Decidir qué es relevante y qué no lo es, qué cuenta y qué no como diferencia, significa regular de manera diferente determinados comportamientos y no otros, significa tratar de manera igual o diferente ciertos individuos o clases de individuos, en vez de otros u otras ${ }^{7}$. Desde este punto de vista constituyen un caso paradigmático las normas especiales de favor (como por ej. las normas que establecen facilidades fiscales o simplifican ciertos procedimientos administrativos para los entes que pertenecen a una determinada Iglesia, o a una determinada confesión religiosa que ha estipulado un acuerdo con el Estado Italiano, o a entidades eclesiásticas ${ }^{8}$ ).

Para no olvidar esta triple dimensión de la especialidad (lógica, semántica y de justicia) y, además, para no olvidar que los términos determinantes de la especialidad

5 Hablo de «reconstrucción», porque, evidentemente, fuera del ámbito de los lenguajes formales, como la lógica y la matemática, los conceptos no son exactamente o precisamente determinados por reglas de interpretación fijas y previas, como sucede con los símbolos en lógica y, se supone, también con las clases lógicas y los conjuntos.

6 Así, si tenemos en cuenta que las acciones de sociedad son títulos de crédito, resulta dudoso si la disciplina del conflicto relativa a los títulos de crédito en general del art. 59 1. 218/1995, se refiere también a aquella particular categoría constituida por títulos participativos accionarios, o si, en cambio, estos últimos deban ser regulados por la lex societatis conforme al contenido del art. 25 1. 218/1995. La alternativa es entre dos clasificaciones diferentes y, por lo tanto, depende de la identificación de géneros y diferencias específicas relevantes. La aplicación a las acciones de la lex tituli se depende de incluirlas en el género de los títulos de crédito; la aplicación de la lex societatis se fundamenta, en cambio, sobre su pertenencia al género de la sociedad. Cfr. por ejemplo Malatesta, 2011: 491; BAREL y ARMELLINI, 2011: 130; GARDELLA, 2007: 78-79, nota 165.

7 Por un lado, la generalidad es justicia en el sentido de tratamiento indiferenciado, por otro lado, también la especialidad es justicia en el sentido de tratamiento diferenciado, hasta el caso extremo del tratamiento específico para el caso individual.

${ }^{8}$ Cfr., por ejemplo, CASuscelli, 2012: 17 y ss.; Fiorentino, 2012: 117 y ss. 
jurídica son aquellos elementos conceptuales de las normas que los intérpretes consideran relevantes, es útil distinguir la relación de especialidad entre normas, por un lado, y la relación de género a especie como uno de esos elementos, por el otro.

En base a esta última relación, toda especie hereda los caracteres del género y se distingue de las otras especies por una diferencia específica que, en el género puede o no estar. Es decir, una característica que no es ni necesaria ni suficiente para pertenecer al género. Por ejemplo, los gatos pueden ser negros y pueden ser blancos; existe, la especie de los gatos blancos y la especie de los gatos negros. Pero ni el ser blanco ni el ser negro son características suficientes o necesarias para ser gato; existen de hecho gatos siameses y perros blancos.

Entre las normas especiales y generales existe una relación que tiene la forma de la consecuencia lógica. Esta relación se puede expresar diciendo que, por ejemplo, la obligación de honrar al padre y a la madre presupone (lógicamente) la obligación de honrar un pariente cercano o bien que honrar un pariente cercano es condición (sólo) necesaria de honrar al padre y a la madre. Las dos relaciones, de inclusión de la especie (el padre y la madre) en el género (un pariente cercano, por ejemplo) y de consecuencia lógica entre normas, pueden ser presentadas de manera unitaria mediante la relación de implicación estricta de C. I. LEWIS ${ }^{9}$. Esta relación puede expresarse del siguiente modo: si el concepto de padre y madre está incluido en el concepto de pariente cercano, es internamente contradictorio afirmar que se honra al padre y a la madre, pero no a un pariente cercano, y es por eso necesario honrar a un pariente cercano, para que sea posible honrar al padre y a la madre ${ }^{10}$.

Configurar la especialidad como implicación estricta tiene la ventaja tanto de mostrar el fundamento semántico de la especialidad, como de distinguir entre el nivel de las normas y el nivel de sus elementos conceptuales. Distinguir entre los dos niveles es necesario porque la especialidad jurídica cambia en función de los elementos conceptuales que los intérpretes consideren relevantes. Y normalmente, no todos los elementos cuentan, a sus ojos, a los fines de la especialidad de las normas.

Por ejemplo, todos consideran que la norma «está prohibido introducirse en una habitación ajena contra la voluntad expresa o tácita del propietario, o bien clandestinamente, o con engaño», es general respecto de la norma (especial) «está prohibido a los funcionarios públicos introducirse en los lugares indicados por la norma precedente, abusando de los poderes inherentes a sus propias funciones» ${ }^{11}$. Ello se debe a que se da relevancia (se consideran como términos determinantes) el destinatario de las nor-

9 Para profundizar, vid. ZoRZETTO, 2010: 83-158.

10 En el ejemplo, el deber general de honrar un pariente cercano resulta satisfecho cualquiera sea el pariente cercano que se honra. Como indica el artículo indeterminado «un» todas las posibles diferencias específicas de cada pariente cercano (entendido como especie o también individuo) son igualmente indiferentes. Por eso, respetando el deber especial de honrar al padre y a la madre, se respeta también, por definición, el deber general. Diferente es el caso de la norma que impone la obligación de honrar los parientes cercanos, entendidos como todos los parientes cercanos, no (por lo menos) uno. En este caso, honrando al padre y a la madre se observa sólo la norma especial, no la norma general. Para observar también esta última es necesario honrar el resto de los parientes cercanos. Se sigue que quien observa la norma especial resultará destinatario de la eventual sanción conectada a la inobservancia de la norma general.

${ }^{11}$ Cfr. arts. 614 Violación de domicilio y 615 Violación de domicilio cometida por funcionario público CP it. 
mas (cualquier persona y el funcionario público) y el modo en que el funcionario público actúa (abusando de sus poderes), mientras no se cuentan (no se consideran como términos determinantes a los fines de la relación de especialidad), las modalidades de la acción contra la voluntad expresa o tácita del propietario, o clandestinamente, o con engaño. Si se considerasen también éstas, tendríamos dos normas que tienen algunos aspectos en común y otros no, y por lo que se superponen, pero no tendríamos normas especiales y generales ${ }^{12}$.

Tanto los juristas como los teóricos suelen también basar la especialidad sobre elementos externos a los supuestos de hecho previstos por las normas. Elementos que, de todos modos, son tratados como elementos implícitos de las normas y esenciales a los fines de la especialidad. Además del caso inicial de las normas convencionales o consuetudinarias internacionales, donde a los fines de la especialidad es determinante su origen o modalidad de formación, otra hipótesis muy difundida tiene que ver con la llamada materia, o sea el campo de aplicación material de las normas que el intérprete les atribuye.

Por ejemplo, de los arts. 77, Representación del procurador y del agente y 317 Representación frente al juez de paz del Cod. Proc. Civ. it. (art. 77 «El procurador general y aquel predispuesto para determinados negocios no pueden estar en juicio por el proponente, cuando este poder no les haya sido conferido expresamente, por escrito, excepto para los actos urgentes y para las medidas cautelares», art. 317 «Frente al juez de paz, las partes pueden hacerse representar por personas dotadas de mandato escrito a pie de pagina de la citación o en acto separado, salvo que el juez ordene su comparecencia personal»), la doctrina y la jurisprudencia extraen, respectivamente, las siguientes normas:

$(\mathrm{Ng})$ [En cada juicio civil], las partes pueden hacerse representar, mediante un poder en forma escrita, solamente por una persona que tiene también poder representativo sustancial;

(Ns) [En el procedimiento civil], frente al juez de paz, las partes pueden hacerse representar por una persona dotada de mandato escrito, aunque no tenga poder representativo sustancial.

La primera norma es considerada general en cuanto aplicable (principalmente, y salvo derogación expresa) a todo juicio civil. La segunda norma es considerada especial porque, en cambio, es aplicable sólo a los procedimientos civiles frente al juez de paz. Aquí es determinante, para la construcción de la relación de género a especie, el ámbito de aplicación material de las normas; y no la línea de conducta prescripta, o sea, el poder de conferir poder a las partes. Si consideramos este aspecto, el poder de representación atribuido por la primera norma general es más delimitado (menos extenso, más específico), en vez del poder más genérico atribuido por la segunda norma especial. Para la norma especial, la representación en juicio puede ser conferida a cualquier persona (siempre que sea con poder escrito). Para la norma general, esta formalidad no alcanza; es necesario también que el representante procesal sea además representante

12 Esta situación es a menudo llamada «especialidad bilateral» o «recíproca», a pesar que la relación lógica correspondiente no es la de inclusión de una clase infra-ordenada en una sobre-ordenada, o de un conjunto menos extenso en uno más extenso, sino que se trata de la interferencia entre clases o conjuntos. 
sustancial (i.e. procurador general o agente predispuesto para determinados negocios). Respecto de la norma especial, la norma general exige, por lo tanto, un requisito adicional (y no uno menos) para ejercitar válidamente el poder que regula. De este modo, la generalidad de los sujetos (o sea, las partes en un juicio civil) tiene una carga en más (y no una en menos) respecto de las que tiene la particular clase de sujetos constituida por las partes en un juicio civil que actúan delante del juez de paz.

Como resulta de este ejemplo, distinguir entre (especialidad de las) normas y (relación de género a especie entre los) términos determinantes permite también explicar el fenómeno - por otra parte bastante común- de las normas especiales más genéricas de las normas generales y viceversa ${ }^{13}$.

Otra actitud común en los juristas y teóricos es la de considerar, en general, como relevante a los fines de la especialidad, el elemento que fija el destinatario de las normas. Este elemento no sólo cuenta casi siempre, sino que a menudo es más relevante que otros elementos y a veces es incluso decisivo. En cambio, tendencialmente, todo otro elemento resulta ser o no ser relevante según las asunciones iniciales, caso por caso. Generalmente no son relevantes la consecuencia o los efectos jurídicos. Por eso, por ejemplo, para clasificar las normas penales en especiales y generales se toma en cuenta la forma categórica «está prohibido que $p$ » en lugar de la forma hipotética «si $p$, entonces se está sujeto a la pena $x \gg$. De este modo, la especialidad resulta trazada solo del lado del supuesto de hecho (la llamada figura criminis), mientras que la consecuencia de la norma penal, o sea la pena, no constituye una diferencia específica ulteriormente relevante. También en el derecho civil, los juristas tienden a calificar las normas como especiales o generales en razón del supuesto de hecho, omitiendo considerar a los fines de la especialidad las consecuencias (si bien éstas son relevantes a los fines de estable-

13 Otro ejemplo se obtiene a partir de la comparación entre los arts. $182,1 .^{\circ}$ y 2 . $^{\circ}$ inc. y $421,1 .^{\circ}$ inc., Cod. Proc. Civ. it. El primer artículo dispone que «1. El juez instructor verifica de oficio la regularidad de la constitución de las partes y, cuando es necesario, los invita a completar o a poner en regla los actos y los documentos que estime defectuosos. 2. Cuando advierte un defecto de representación, de asistencia o de autorización o bien un vicio que determina la nulidad del poder de representación del defensor, el juez confiere a las partes un término perentorio para la constitución de la persona a la cual compete la representación o la asistencia, para la concesión de las autorizaciones necesarias, o bien para la concesión de la representación en el litigio o para la renovación de la misma. omissis». El segundo artículo dispone que «El juez indica a las partes en cada momento las irregularidades de los actos y de los documentos que pueden ser sanadas confiriendo un término para que provean a ello [...]». La primera disposición, según los estudiosos italianos, enuncia una norma general porque se refiere al proceso civil ordinario de primer grado frente al Tribunal (que es considerado el tipo general paradigmático de proceso), la segunda expresa para todos una norma especial, porque se refiere al proceso civil ordinario de primer grado según el rito del trabajo. También en este caso es esencial, por lo tanto, a los fines de la especialidad el campo de aplicación material de las dos normas; considerando la línea de conducta prescripta de las dos normas, la norma general es mucho más específica que la norma especial que tiene contenido mucho más genérico. Otro ejemplo está dado por el art. 43, 3. ${ }^{\circ}$ inc., RD de 16 de marzo de 1942, n. 267, según el cual «La apertura de la quiebra determina la interrupción del proceso» (se habla de extinción automática) y por el art. 300 Cod. Proc. Civ. según el cual en caso de pérdida de la capacidad de la parte constituida «mediante procurador, éste lo declara en audiencia o lo notifica a las otras partes. Desde el momento de tal declaración o notificación el proceso es interrumpido, excepto si se produce la constitución voluntaria o la readmisión» por parte de aquellos a los que compete continuarlo. En la primera disposición, la doctrina y la jurisprudencia italiana leen una norma especial, respecto a la norma formulada en el Código de procedimiento civil, en cuanto la quiebra es considerada una particular hipótesis de pérdida de capacidad. La norma especial es más genérica que la norma general, porque para esta cualquier declaración o notificación es indiferente, tan así que, aun cuando tenga lugar, el dies a quo para continuar el juicio no transcurre desde aquel momento, sino desde el de la sentencia de quiebra. 
cer si la norma especial deroga o no, y por lo tanto si las consecuencias se acumulan o no). Así, por ejemplo, la norma según la cual «si por circunstancias imprevisibles se verifican aumentos o disminuciones en el costo de los materiales o de la mano de obra, tales como para determinar un aumento o una disminución superior al diez por ciento del precio total convenido para la obra, entonces el contratista o el comitente pueden pedir una revisión del precio por la diferencia que excede el diez por ciento» (cfr. art. 1664 CC it.) es considerada especial respecto de la norma general según la cual «si en un contrato a ejecución continuada o periódica la prestación de una de las partes resulta excesivamente onerosa por verificarse eventos extraordinarios e imprevisibles, entonces la parte que debe tal prestación puede pedir la resolución del contrato». La especialidad está construida a partir del supuesto de hecho, concibiendo los aumentos o disminuciones, objeto de la primera norma, como una especie del género excesiva onerosidad sobrevenida, objeto de la segunda ${ }^{14}$.

A pesar de este hábito de los juristas y los teóricos, de trazar la relación de especialidad entre los supuestos de hecho de las normas (entendidos en sentido amplio, ya que se incluye, como he señalado, la esfera material, temporal o espacial, etc.), también las consecuencias o los efectos jurídicos y las modalidades de calificación deóntica podrían ser términos determinantes de la especialidad jurídica.

Podemos dar tres ejemplos elementales para cada hipótesis: a) la norma «si no se respetan las órdenes paternas, entonces se recibirá un castigo», es especial, en virtud del supuesto de hecho, respecto de la norma «si se transgrede una orden, entonces se recibirá un castigo»; b) la norma «si se usa el molino del Señor para moler el trigo, entonces se debe pagar una tasa en proporción a la cantidad de trigo molido», es especial en virtud de la consecuencia respecto de la norma «si se usa el molino del señor para moler el trigo, entonces se debe pagar un canon»; c) la norma «es obligatorio votar», es especial en virtud de la modalidad de calificación deóntica respecto de la norma «está permitido votar», puesto que solo si está permitido votar, votar puede ser obligatorio.

La norma especial es necesariamente compatible con la norma general, primero, en todos los casos en que la norma especial es una especificación de la norma general, que tiene la misma modalidad de calificación deóntica y referencia, en relación de especie a género, respecto a aquella de la norma general, como en el ejemplo «está prohibido causar molestias a los condóminos del edificio» y «está prohibido jugar en el jardín en las horas de descanso establecidas en el reglamento condominial»; y segundo, en todos los casos en que los términos determinantes en relación de género a especie son precisamente las modalidades de calificación deóntica de las normas, como en el caso de la obligación

${ }_{14}$ Para la jurisprudencia italiana la norma especial del art. 1.664 CC it. deroga la norma general del art. 1.467 del CC it. Ello sirve para evitar, debido a la diversidad de las consecuencias, que en los casos de excesiva onerosidad sub specie de aumentos o disminuciones en el costo de los materiales o de la mano de obra, tales como para determinar un aumento o una disminución superiores al diez por ciento del precio, exista la posibilidad de pedir en, vía alternativa, o bien la resolución, o bien la revisión. Precisamente, para evitar la posibilidad de este cúmulo alternativo de demandas, «con referencia al contrato de licitación, dada la existencia de una disciplina especial al respecto (art 1.664 CC), [...] el remedio resolutorio previsto por el art. 1.467 CC, puede considerarse aplicable [...] sólo en el caso en que la onerosidad sobrevenida sea atribuida a causas diferentes de aquellas mencionadas en el art. 1.664, debiendo en todo otro caso prevalecer la norma especial sobre la norma general, en cuanto constituye la disciplina específica de un contrato conmutativo con características particulares» (T. NAPOli-FratTAmagGioRe, 13 luglio 2007, en Strum. avv., 2007, 1: 53 ). 
de vacunación, que presupone el permiso de vacunarse (permiso positivo); en efecto, sólo si está permitido vacunarse, entonces vacunarse podrá además ser obligatorio. Se habla en estos casos de relación de infra/sobre-implicación o infra/sobre-alternación. Analógicamente, sólo si está permitido no explotar el trabajo infantil (permiso negativo), podrá también estar prohibido explotar el trabajo infantil; cada prohibición presupone lógicamente un permiso negativo, o sea, una facultad de abstención.

Excepto estos casos, cada norma especial puede ser, o bien compatible, o bien incompatible, respecto de cada norma más general, según cuáles sean las modalidades de calificación deóntica de las normas en cuestión. Por ejemplo, respecto al permiso general, dirigido a todas las personas, de expresar públicamente el propio pensamiento, son especiales tanto la norma que permite hacer propaganda a favor de un determinado partido político (norma especial compatible), como aquella que prohíbe, en discursos públicos, lanzar insultos ofensivos al honor o a la reputación (norma especial incompatible).

\section{LA DEROGACIÓN}

Corolario de esta concepción de la especialidad es que ninguna norma especial, en sí misma, deroga la norma más general, porque la derogación - a diferencia de la especialidad/generalidad - no es una cuestión lógico-conceptual, inherente a las normas (y, básicamente, a sus elementos), sino que es una cuestión de derecho positivo referida a la elección de las normas con las que decidir cada caso. La podemos llamar una elección de justificación externa, en oposición a la justificación interna con la que se obtiene la conclusión práctica del caso. Los adjetivos «externa» e «interna» indican, con una metáfora espacial, una sucesión lógica. Para obtener una conclusión práctica (es decir, una norma singular o individual) es necesario antes determinar/elegir la norma (general) que será adoptada como base del razonamiento o como fundamento de la justificación. La cuestión que resuelve el principio de la lex specialis es precisamente si, en la justificación jurídica, se deban adoptar las normas más especiales o aquellas más generales.

Por ejemplo, para decidir o saber si a un trabajador le es debida o no la retribución correspondiente al ejercicio de tareas superiores a aquellas por las cuales ha sido contratado, ¿se debe elegir la norma general según la cual «el trabajador tiene derecho a una retribución proporcionada a la cantidad y calidad de su trabajo» (cfr. primera parte art. 36 Const. it.) o la norma especial que prevé que «el desarrollo de tareas superiores respecto a la tarea del cargo comporta el derecho a las diferencias retributivas»? ${ }^{15}$. Según qué norma elijamos, serán correctos o incorrectos, conformes o no a derecho, comportamientos diferentes (a propósito, es interesante notar que la jurisprudencia considera necesaria, en este caso, la norma especial expresa, excluyendo que sea posible derivar de la norma general, ex art. 36 Const., el derecho al aumento de la retribución en virtud de las tareas efectivamente desarrolladas) ${ }^{16}$.

15 Cfr. art. 56 d.lgs. n. 29/1993, como sust. por el art. 25 d.lgs. n. 80/1998 y mod. del art. 15 d.lgs. n. 387/1998.

16 Vid. C. Stato, sez. VI, 3 febrero 2011, n. 758, en Foro amm.-Cons. Stato, 2011: 528, versión completa en banco de datos Pluris Utet y los precedentes mencionados en la motivación. 
Las dos normas del ejemplo se refieren (al derecho) a la retribución del trabajador y el problema es precisamente saber si sólo una, o ambas, sirve/n para regular tales casos. A tal fin, es necesario distinguir entre la calificación jurídica, por un lado, y la justificación jurídica, por el otro. O sea, es necesario distinguir entre la aplicabilidad interna de las normas, es decir, qué es jurídicamente relevante o significativo para un determinado derecho, y la aplicabilidad externa de las normas, es decir, en base a qué normas se debe actuar o decidir según un determinado derecho. La primera cuestión es lógicamente anterior respecto de la segunda; en este sentido, las normas califican en función de la acción o, para decirlo brevemente, son razones para la acción ${ }^{17}$.

La respuesta a la pregunta «¿por qué está prohibido construir un balcón en la fachada de un condominio?» ${ }^{18}$ puede ser «porque cada participante no puede servirse de la cosa común alterando la destinación e impidiendo a los demás participantes de hacer igual uso según su derecho» (norma general prohibitiva), o bien, «porque está prohibido abrir sobre la fachada de un condominio luces y vistas directas, laterales u oblicuas que produzcan una alteración estética y modifiquen la decoración arquitectónica del edificio» (norma especial prohibitiva). En tal caso, en ausencia de derogación, tendremos dos razones concurrentes para no construir el balcón. La respuesta a la pregunta «¿entro o no entro en la propiedad privada ajena para salvar la vida de Tizio?» puede ser, ya sea «sí, porque en estado de necesidad está permitido acceder a lugares privados», o bien «no, porque está prohibido violar la propiedad ajena». En este último caso, en ausencia de derogación por especialidad, el agente se encuentra frente a un dilema práctico, es decir, enfrenta dos respuestas normativas incompatibles.

Ya sea que tengamos dos o más razones/normas concurrentes (como en los dos ejemplos de la retribución y del condominio), ya sea que tengamos, en cambio, razones/normas incompatibles (como en el último ejemplo del estado de necesidad), depende del derecho positivo qué norma seguir/adoptar — la (más) general, la (más) especial, o las dos- para decidir cómo debe uno comportarse. Para elegir entre esas normas es necesaria una tercera norma, diferente y distinta. En la cultura jurídica europea continental contemporánea y no sólo, la enunciación más famosa de esta tercer norma es, precisamente, el adagio o máxima «lex specialis derogat legi generali».

Un derecho positivo podrá entonces elegir entre las siguientes opciones:

i) Que toda norma especial derogue a toda norma más general, adoptando la conocida máxima con relación a todo el ordenamiento o sólo con relación a un ámbito o sector (cfr. p. ej., el art. 15 CP italiano y el art. 8 CP español).

ii) Que sólo algunas normas especiales deroguen algunas normas generales adoptando la máxima sólo para casos puntuales (como hace por ejemplo el art. 840

${ }_{17}$ Los juristas positivos tienden a no distinguir entre la calificación jurídica y la justificación jurídica. Esta omisión es una de las razones por las cuáles la norma especial suele ser considerada derogatoria por fuerza propia.

${ }_{18}$ La jurisprudencia aborda esta cuestión considerando relevante la norma en materia de distancias legales entre terrenos contiguos —art. 905 CC—y la norma en materia de uso de la cosa común —art. 1.102 CC-. Esta última es considerada una norma especial referida a una situación de copropiedad, mientras que la primera es considerada general y concerniente a la propiedad en general (cfr. ex multis, Cass. civ., sez. II, 18 marzo 2010, n. 6546, en Giust. civ., 2011, I: 1040). En realidad, a pesar de esta asunción, comparando las normas en cuestión, resulta que éstas están, no en relación de especialidad, sino de superposición. Por eso, en el ejemplo del texto, me alejo del caso real para poder analizar dos normas, una especial respecto a la otra. 
CC italiano, que dispone que la norma según la cual la propiedad del suelo se extiende al subsuelo, con todo lo que contiene, no se aplica a las minas o yacimientos; o como hace art. 2.401 del CC francés en materia de hipoteca legal ${ }^{19}$, y el art. 1.153, del mismo código, en materia de intereses por retraso en el cumplimiento de las obligaciones pecuniarias ${ }^{20}$ ).

iii) Que algunas normas generales deroguen a las eventuales normas más especiales, según el principio inverso lex generalis derogat legi speciali (como históricamente ha sucedido respecto de las costumbres imperiales generales que habían de prevalecer sobre las costumbres locales especiales; o, en el derecho italiano actual, como sucede conforme al art. 9, 1., n. 689 del 1981, que dispone que las normas penales nacionales prevalecen sobre las normas especiales de las regiones o provincias autónomas que prevean sanciones administrativas); o finalmente.

iv) Que las normas especiales y generales no deroguen las unas a las otras, sino que cuando sean «concurrentes», guíen por igual las decisiones prácticas de los ciudadanos y de los jueces y funcionarios públicos (como en el caso del concurso de delitos, o como en el caso del art. 18 del Tratado sobre el Funcionamiento de la Unión Europea (ex art. 12 TCE) según el cual «En el campo de aplicación de los tratados, y sin prejuicio de las disposiciones especiales previstas por los mismos, está prohibida la discriminación en base a la nacionalidad»).

Obviamente, cada derecho podrá luego preveer esto expresamente (en adecuadas disposiciones, como los artículos anteriormente citados), o bien tácitamente (con normas no formuladas).

El principio lex specialis derogat legi generali es, por lo tanto, una regla de decisión contingente, que puede o no ser contemplada por un determinado derecho vigente. Se trata, más precisamente, de una meta-regla sobre la aplicación externa que regula el procedimiento de decisión de los casos jurídicos, sean estos casos reales (casos concretos), sean éstos planteados para ejercicio intelectual (casos abstractos). Por eso, si bien sus destinatarios son principalmente los funcionarios, y sobre todo los jueces, también lo son los ciudadanos, dado que también éstos están evidentemente interesados en saber si a su comportamiento y al de los demás se aplica una sola norma o varias (más o menos generales) o si la única norma aplicable es aquella especial o general.

Piénsese, por ejemplo, las diferentes actitudes prácticas que normalmente se desarrollan en presencia de normas elementales como «está prohibido el acceso a los animales» y «está prohibido el acceso a los perros sin bozal y correa». Se trata de dos normas destinadas a sus amos o acompañantes, cuyas actitudes prácticas serán muy diferentes dependiendo de si la segunda norma deroga o no a la primera. Además, en presencia de normas semejantes, en donde la norma especial tiene como objeto no una especie, sino una sub-especie (no los perros tout court, sino los perros sin bozal y

19 Cfr. Art. 2.401 Code civil (Version consolidée au 2 juin 2012): «Sous réserve tant des exceptions résultant du présent code, d'autres codes ou de lois particulières que du droit pour le débiteur de se prévaloir des dispositions des articles 2.444 et suivants, le créancier bénéficiaire d'une bypothèque légale peut inscrire son droit sur tous les immeubles appartenant actuellement à son débiteur, sauf à se conformer aux dispositions de l'article 2.426».

${ }^{20}$ Cfr. Art. 1.153 Code civil (Version consolidée au 2 juin 2012): «Dans les obligations qui se bornent au paiement d'une certaine somme, les dommages-intérêts résultant du retard dans l'exécution ne consistent jamais que dans la condamnation aux intérêts au taux légal, sauf les règles particulières au commerce et au cautionnement». 
correa), a menudo se presenta el problema de si no ha sido regulada de manera opuesta la clase complementaria, y por lo tanto, si el acceso a los perros con bozal y correa deba entenderse implícitamente permitido. Cuando la diferencia específica que identifica la sub-especie parece ser la razón decisiva de la prohibición (o de la obligación, o del permiso, etc.), se tiende a responder de manera afirmativa.

De lo dicho hasta aquí se sigue que la tesis usual según la cual las normas especiales y generales son incompatibles da cuenta sólo parcialmente de la especialidad jurídica, ya que excluye una parte importante de tal fenómeno. Igualmente, concebir el principio de especialidad como un principio de solución de las antinomias pone a la luz sólo una de sus funciones, desde el momento que ese principio puede ser empleado también para evitar la aplicación conjunta de normas especiales y generales compatibles.

Además, una cosa es la especialidad, y otra cosa es la derogación. Y por lo tanto, las normas especiales pueden o no derogar las normas generales. En efecto, en función de la relación de especialidad, por un lado, toda norma general se refiere a lo que se refiere también toda norma más especial; por otro lado, toda norma especial califica una parte de los casos calificados también por toda norma mas general. Por tanto, tanto la norma especial como la general son, la una respecto de la otra, redundantes sobre el plano de la aplicabilidad interna, o sea respecto de la calificación jurídica ${ }^{21}$. Presupuesto de aplicación del principio de la lex specialis no es entonces la incompatibilidad entre las normas especiales y generales, sino la existencia de un ámbito común de calificación (o aplicabilidad interna), dado precisamente por la especie ${ }^{22}$.

Si las normas en juego son compatibles y no derogantes, tendremos una redundancia, tanto sobre el plano de la aplicabilidad interna, como sobre el plano de la aplicabilidad externa y, por lo tanto, se verificará un concurso de normas y la consecuente acumulación de consecuencias. Si las normas en juego son incompatibles y no derogantes, tendremos una redundancia que genera un dilema práctico. Si una de las dos normas (por ejemplo la especial) deroga a la otra (la general), en virtud de un criterio jerárquico (por ejemplo el principio de la lex specialis), tendremos redundancia sólo sobre el plano de la aplicabilidad interna, o sea de la calificación jurídica.

La incompatibilidad no es ni siquiera la razón de la derogación. Ello en cuanto, en base al principio de la lex specialis, la norma especial prevalece sobre la norma general, no porque sea incompatible, sino porque es especial. La especialidad, no la incompatibilidad, es la razón de la derogación. Naturalmente, pueden existir otras razones en virtud de las cuales una norma (especial) prevalece sobre las normas más generales, como por ejemplo, porque es más favorable, porque ha sido emanada por una determinada autoridad, etc. En tales hipótesis, la meta-regla sobre la aplicación que está en juego no es el principio de la lex specialis, sino el criterio de prevalencia de la norma más favorable (criterio de la ley más favorable) o de competencia, etcétera.

21 Son normas redundantes también las normas que se encuentran en relación de superposición (cfr. supra nota 11), como por ejemplo la norma que obliga a los estudiantes de derecho y de letras estudiar filosofía del derecho, y la norma que impone estudiar por lo menos una materia filosófica en la facultad de derecho.

22 Existe espacio para la derogación también en las situaciones de «especialidad bilateral» o «recíproca». En virtud de lo dicho ( $c f r$. supra notas 11 y 20), en esta hipótesis la razón de la derogación no podrá ser la especialidad; podrá ser, en cambio, por ejemplo, el trato más o menos riguroso, el trato de favor o la ventaja para una determinada categoría, etcétera. 
Vale la pena agregar que, tratándose de la aplicación de normas especiales y generales, el criterio según el cual debe aplicarse la disciplina más ventajosas es a veces empleado también para excluir la derogación entre normas especiales y generales. Así, por ejemplo, en materia de ley aplicable a la filiación, el art. $33,1 .^{\circ}$ y $2 .^{\circ}$ inc., de la L. 218/1995 dispone que «1. El estado de hijo se determina por la ley nacional del hijo al momento del nacimiento ${ }^{23}$. 2. Es legítimo el hijo considerado tal por la ley del Estado del cual uno de los padres es ciudadano al momento del nacimiento del hijo». En el segundo inciso se ve una norma especial respecto de la formulada en el primer inciso, porque mientras esta última tiene que ver con el estado de hijo legítimo, la otra se refiere al estado de hijo. Parte de los intérpretes, a partir de los trabajos preparatorios, pero sobre todo por razones de privilegio para con el estatus de hijo legítimo (c.d. favor filiationis, sub specie legitimationis) ${ }^{24}$, afirman que la norma especial no deroga a la norma general; en particular, la mención a la ley nacional de los padres (cfr. $2 .^{\circ}$ inc.) no influiría sobre la aplicabilidad de la ley nacional del hijo y, en vía subsidiaria, de la ley del Estado del cual uno de los padres es ciudadano. En sentido opuesto, parte de los intérpretes considera que la condición de hijo legítimo es regulada exclusivamente por las leyes de los padres (ex 2. ${ }^{\circ}$ inc. cit.). En este último caso, la norma especial derogaría por lo tanto la norma general. Dependiendo de la posición, se argumenta a favor de una u otra conclusión ya sea sobre la base de un argumento sistemático y $a$ contrario de los artículos en materia de filiación ${ }^{25}$, ya sea sobre la base de que el estatus de hijo legítimo estaría conectado más a la relación matrimonial de los padres, que no a la filiación natural. Nótese que en tal caso se usan dos teorías de los géneros y de las especies diferentes, una dirigida hacia la especialidad, la otra dirigida hacia la derogación. En el primer caso, como hemos dicho, se asume que el estado de hijo legítimo está incluido en el estatus de hijo (género-1). En el segundo caso, se asume en cambio que la legitimación es una implicancia del matrimonio (género-2).

\section{LAS REDUNDANCIAS LINGÜÍSTICAS EN LOS LENGUAJES NATURALES}

Como es sabido, mediante la noción de redundancia se suele identificar en lingüística, al mismo tiempo, un fenómeno muy general (y, según algunas posiciones, una característica esencial) de los lenguajes naturales ${ }^{26}$ y una amplia serie de fenómenos

\footnotetext{
${ }^{23}$ Me limito a señalar, ya que es extraño al tema de mi análisis, la evidente circularidad de este criterio de conexión.

${ }^{24}$ Es interesante notar que aquí el concepto de «ventaja» no significa mejor trato o trato más ventajoso para la categoría de los hijos, en cuanto no importa cuál es la ley, por ejemplo, que permita una verificación más fácil o rápida de la filiación natural. La ventaja está en ampliar el número de las leyes aplicables a la filiación. La asunción implícita de la que se parte es que la existencia de un mayor número de criterios de conexión favorezca la comprobación del estatus de hijo. Como diré en el texto, esta asunción es desbaratada, en el caso de especie, por la circunstancia que los criterios son entendidos no como alternativos, sino como el uno subsidiario del otro, y es evidente que en abstracto no se puede saber si la ley del (presunto) hijo hace más fácil o, en cambio, más difícil la comprobación de la filiación natural respecto a aquella de los (presuntos) padres.

${ }^{25} \mathrm{Cfr}$. arts. $34,1{ }^{\circ}$ inc., y $35,1{ }^{\circ}$ inc., de la L. 218/1995, en tema de legitimación por matrimonio sucesivo y de reconocimiento del hijo natural que, a diferencia del art. $33,2{ }^{\circ}$ inc., se refieren expresamente a la ley nacional del hijo.

${ }^{26}$ Cfr. Pulgram, 1983: 107; Chiari, 2002.
} 
micro- y macro-lingüísticos. La noción de redundancia lingüística es por eso una noción, primero, genérica y, segundo, notablemente ambigua ${ }^{27}$. En base a una definición estándar, en la lingüística contemporánea el término «redundancia» designa la reiteración de elementos lingüísticos que hace que una información ya dada, sea vehiculada bajo otra forma ${ }^{28}$. La redundancia es por eso generalmente vista como «the amount of linguistic signals exceeding the minimum necessary in order to render the messagge» ${ }^{29}$; «l'identité ou la quasi-identité des signifiés produit de la redondance, soit, au sens le plus large, l'itèration d'un même contenu» ${ }^{30}$. A causa de esta genericidad, muchos, si no todos los fenómenos de redundancia lingüística son habitualmente también catalogados bajo otros nombres. Trayendo a colación algunos de esos nombres, entre los más conocidos, se encuentra el de pleonasmo ${ }^{31}$, perisología ${ }^{32}$, tautología, repetición, iteración, superfetación, elementos expletivos ${ }^{33}$, dummies elements ${ }^{34}$, híper-caracterización del signo lingüístico ${ }^{35}$, abundantia, commoratio, expolitio ${ }^{36}$, etcétera.

Para analizar y clasificar los fenómenos de redundancia de los lenguajes naturales, han sido propuestas numerosas distinciones, basadas sobre criterios heterogéneos, de naturaleza lógico-semántica, léxica, sintáctica, morfológica, fonética, cada una de las cuales denota un método de análisis diferente y una concepción distinta del origen, la naturaleza y el funcionamiento de los lenguajes naturales y del lenguaje. Declaro previamente que no privilegiaré, ni propondré, el uso de una teoría en particular, porque creo que prestar atención a diferentes enfoques pueda ser útil para una mejor comprensión del fenómeno de la redundancia en el lenguaje jurídico.

Dicho esto, veamos entonces algunos tipos principales de redundancias que han sido identificadas por los lingüistas ${ }^{37}$ :

i. La redundancia sintáctica, relativa a la repetición de signos (morfemas-grafemas), respecto de la cual se identifican, por ejemplo: (i) la redundancia sistemática relativa a los operadores morf, tales como «si», «en el caso que», «en la medida en que», y que se refiere a la presencia de estructuras gramaticales con la misma función; (ii) la redundancia sintagmática que depende de la linealidad del texto y que concierne a la

${ }^{27}$ Quizá el único punto que, sobre la redundancia, se puede considerar pacífico en lingüística es que «cependant n'est pas la caractéristique d'un élément isolé, mais d'une séquence d'éléments. La redondance serait nulle si tous les mots dans une suite étaient également probabile», PeLCHAT, 1983: 78.

${ }^{28}$ Cfr. Śabrîula, 1975: 101.

29 Cfr. PANeK, 2009: 82, donde cita KIELAR, 1973 (non vidi).

30 «La redondance peut servir notamment à s'assurer de la bonne transmission et réception du contenu en contrant le bruit, c'est-à-dire les obstacles à ceux-ci (ou encore à la comprébension du contenu)», HÉBERT, 2012: 160 . reforzarla.

${ }^{31}$ Figura de estilo que consiste en usar más palabras de lo necesario para expresar una idea con el fin de

${ }^{32}$ Figura retórica que designa el uso de un pleonasmo sin intención literaria.

33 Cfr. http://www.accademiadellacrusca.it.

34 En base a la noción estándar «a dummy sign [...] is defined as a sign lacking the signified» (cfr. EL KASSAS, 2011). Es usual señalar como ejemplos típicos de estos «elements with no semantics», el «expletive "it", or the copula "is", in some of its manifestations in English» (cfr. CARSTON, 2008: 74). Como se sabe, es extremadamente controvertido en semiótica si pueden existir elementos simbólicos semánticamente vacíos (símbolos $\sin$ significado).

35 Cfr. p. ej., SORNICOLA, 1995: 56.

36 Cfr. CATERina y LANTELLA, 2011: 477 y ss.

37 No trataré la redundancia fonológica, relativa por lo tanto a los fonemas; trataré solo la redundancia lingüística relativa a los morfemas y lexemas de un determinado lenguaje y su uso. 
frecuencia de los elementos de un nivel (grafema) y se origina en las restricciones a nivel morfológico y sintáctico (por ejemplo, uso de afijos y sufijos y la reacción); (iii) la redundancia morfológica sintagmática o lineal que se presenta, por ejemplo, en los fenómenos de concordancia; (iv) la redundancia sintagmática funcional facultativa ${ }^{38}$ que se realiza por ejemplo con la reduplicación del objeto o del sujeto y con la doble negación; (v) la redundancia distributoria o combinatoria relativa al orden de las palabras; (vi) la redundancia paradigmática que depende del repertorio de elementos, a nivel de lexemas, presentes en el sistema lingüístico, y del nivel de uso y del grado de saturación del sistema.

ii. La redundancia semántica, relativa a las propiedades semánticas de los signos y las relaciones conceptuales entre sus significados. Que, en su dimensión de redundancia lógica, se caracteriza por los nexos de implicación y presuposición entre conceptos, y, en su dimensión de redundancia conceptual, es relativa a la sinonimia y cercanía de elementos de significado ${ }^{39}$.

iii. La redundancia pragmática o contextual o enunciativa ${ }^{40}$ (a veces denominada también retórica) ${ }^{41}$, relativa al concreto uso que de la lengua hagan los usuarios en un específico contexto comunicativo. A nivel pragmático, la redundancia puede referirse tanto al canal o medio comunicativo empleado, como al contenido del mensaje lingüístico tal como resulta formulado/comprendido en aquella particular situación comunicativa (se tendrá en cuenta, por lo tanto, su fuerza expresiva, su elegancia estilística, su mayor o menor felicidad respecto a los objetivos comunicativos del emisor y/o del receptor, etc.).

38 Una distinción fundamental en tema de redundancias lingüísticas es aquella entre redundancias «facultativas» y «obligatorias». Mientras estas últimas son inherentes a la morfología y a la sintaxis del lenguaje mismo, las otras son fruto de las elecciones comunicativas de los usuarios. «El código comprende no sólo las características distintivas, sino también las características configurativas y redundantes que dan origen a las variantes contextuales, y las características expresivas que gobiernan las variantes facultativas» (JAKOBSON, 2002: 87-88). «Los medios de los procesos gramaticales constituyen los aspectos obligatorios del código y, alrededor de ellos, se distribuye la constelación de las otras elecciones, de las redundancias, paralelas a aquellas que observamos en el significante», HeILMAnN, 2002: xxiii.

39 El análisis de las propiedades/relaciones entre los significados de los símbolos es conducida a menudo en la dimensión mini- o micro- semántica, yendo hacia la búsqueda de las semi, de los grafi conceptuales y tavole de las relaciones semánticas o matrices gravitantes alrededor de un morfema según enfoques diferentes de la semántica; por ejemplo las teorías de POTTIER (1974) y de RASTIER (1991, vid. también RASTIER, CAVAzZA y ABEILLÉ, 1994: 111-139) o bien la teoría de la gramática transformacional (cfr. LANGEHDOEN, 1967: 303-314) o un enfoque fundamentalmente constructivista del lenguaje basado en las teorías de UlLMANN, KaTZ y McCaWley (cfr. Droste, 1976: 5-33). Vid. también Canon-Roger, 2006; Wierzbicka, 1993: 9-23; id., 2007.

40 Por lo general se contrapone la redundancia enunciativa a la redundancia gramatical. Esta última depende de la estructura del sistema lingüístico, abstrayéndose de sus posibles usos lingüísticos, y depende por lo tanto de las restricciones impuestas por las reglas morfológicas y sintácticas del lenguaje. Tal distinción es a veces asociada a la oposición entre langue y parole.

${ }^{41}$ Cuando se habla de «redundancia retórica» se asume, a menudo, una concepción de la pragmática como análisis, no semiótico sino, causal-socio-psicológico de los contextos comunicativos, poniendo acento prevalentemente en los efectos estilísticos y expresivos de los mensajes. En una acepción negativa - propia también del lenguaje ordinario - se habla de «redundancia» y de «redundancia retórica» para subrayar un vicio o defecto de la comunicación, consistente en el uso excesivo y desproporcionado de elementos lingüísticos respecto de aquellos que exigirían las circunstancias comunicativas específicas. En este sentido, redundante es sinónimo de superfluo, inútil, superabundante, etc. (cfr. por ejemplo SulEIMAN, 1980: 119-142). Incluyo en la amplia categoría de las redundancias pragmáticas también esta última acepción despreciativa, porque la superfluidez, la inutilidad, el exceso, etc., tienen que ver con el uso de un determinado instrumento comunicativo considerado respecto del objetivo y del contexto comunicativo, es decir, se aprecia el uso, precisamente, en el plano pragmático. 
Para darnos cuenta de la variedad de fenómenos lingüísticos que son normalmente atribuibles a la categoría de la redundancia lingüística nombro algunos a título de ejemplo:

1. La concordancia entre sustantivo y verbo, o entre sustantivo y adjetivo y/o artículo; como por ejemplo «un veuf malhereux»; «un viudo desconsolado»; «un povero vedovo», donde todos los elementos en cursiva indican el género masculino y el número singular. También la frase «The boys were eating their lunches», en la cual el número plural está reiterado en cada elemento (sujeto, predicado, complemento, adjetivo posesivo) ${ }^{42}$.

2. El refuerzo de los deícticos («esto aqui», «aquello allá»), de conjunciones y, en particular, de la negación («ino be visto nunca uno!»).

3. El uso enfático de componentes pronominales, como por ejemplo «nos», «se», etcétera.

4. La reduplicación pronominal, como por ejemplo «même» ${ }^{43}$.

5. Los elementos paragógicos, como la inserción de una vocal, idéntica a la última vocal precedente, después de una consonante final; por ejemplo la «-i» final del adverbio «imo» en la forma «imòi» ${ }^{44}$.

6. La introducción pleonástica de frases pseudo-relativas como «aquello/-a que está», «aquellos/as que son».

7. Las fórmulas de exordio que contienen verbos en función fática, como por ejemplo «se comunica que», «se hace presente que», etcétera.

8. Las locuciones conjuntivas como «attendu que».

9. Los signos fáticos que tienen funciones de advertencia: «Atención: ...»; «AVISO: ...», «INSTRUCCIONES PARA EL USO: ...».

10. Las formas adverbiales más rebuscadas respecto a aquellas más comunes, como «ovverossia» respecto a «o sea» $\mathrm{u}$ «o bien», «purtuttavia», «even though» respecto a «though», etcétera.

11. El uso conjunto de morfemas lexicales, uno de los cuales contiene elementos más finos o propiedades semánticas que son, o todas o en parte, propias también del otro, como por ejemplo «vegetal» y «verde» ${ }^{45}$; «subir sobre»; «annibilation totale»; «chronique du temps», «applaudir des deux mains», «abuso excesivo», «requisito imprescindible», «aterido de frío», etc.; la casuística atribuible a esta última categoría es amplia y variada, podemos recordar por ejemplo.

11.1. El uso de adjetivos que amplifican una característica ya expresada por el sustantivo al que se refieren, como por ejemplo, en la expresión «volitabant assidui», el adjetivo «assidui» amplifica el carácter insistente y la rapidez del vuelo, ya expresados por el frecuentativo «volitare» ${ }^{46}$.

42 Cfr. HORNING, 1982: 275-281; Id., 1991: 135-145.

${ }^{43}$ Cfr. SORNICOLA, 2006: 1651-1671.

44 Cfr. DE MarTini, 2006: xxx, nota 38.

${ }^{45} \mathrm{Al}$ respecto, con razón, DROSTE sostiene que «[i]t is important to be aware of the interrelatedness of the semantic properties. If an item contains the property (Vegetable), a whole series of related properties may be redundantly specified, either upward (by implication) or downward (by expansion). We may think, for the latter, of (Ea able), (Growing), (Green), (Boil), and the like. And these properties in their turn are interwoven with other features by implication rules or expansion rules; the latter features may well be activated in a certain situation or in relation to a certain context» (DROSTE, 1976: 31). El texto de referencia es STRAWSON, 1974: 17 y ss.

${ }^{46}$ Cfr. Romagnino, 2009-2010: 33. 
11.2. Las determinaciones tautológicas relativas a las unidades de medida, cantidad, extensión, etc., como por ejemplo «40 años de edad», «horario de apertura: desde la hora 14 a la hora 18», «la jornada o el día 27 de octubre», «la suma de 10 euros», y similares ${ }^{47}$.

11.3. Las duplicaciones de algunos adverbios y locuciones adverbiales, como por ejemplo «dentro y no mas allá» y «sólo y exclusivamente», «sólo y único», que son duplicaciones de «dentro» y «sólo»; piénsese también en la combinación del numeral «uno», «una» con «solo», «sola», y en expresiones como «[no me hagas decir] otra cosa más».

11.4. La combinación expresiva de palabras semánticamente afines, unidas en figuras retóricas como la asonancia o la aliteración; por ejemplo «propugnacula pinnae murorum» en la que «pinna» indica las almenas de los muros de una estructura defensiva y es por eso redundante respecto a «propugnácula» ${ }^{48}$.

11.5. Las expresiones perifrásticas, compuestas de varios vocablos que no contribuyen de manera relevante al significado del mensaje, como por ejemplo «gran cantidad económica de dinero», «opinión pública general», «relación bilateral entre dos países».

11.6. La combinación de adverbios, sobre todo los que terminan en «-mente»y expresan la imposibilidad de graduación, con adjetivos que indican propiedades que ya de por sí no admiten graduación, como por ejemplo el ser gratuito, ajeno, lleno, «absolutamente lleno», «completamente abarrotado», «totalmente gratis», etcétera ${ }^{49}$.

11.7. Las precisiones temporales, como «iremos mañana»y «hace un año fuimos», en donde el futuro y el pasado están indicados genéricamente por el predicado, y específicamente por el complemento de tiempo.

11.8. La explicitación de sub-clases respecto de la que denota un sustantivo, a menudo acompañada por conjunciones que funcionan como marcas; como por ejemplo, en las expresiones, «los perros, también los pequeños, e incluso con correa, no pueden entrar» ${ }^{50}$.

11.9. Las proposiciones o expresiones incidentales que tienen una función explicativa y que, eventualmente, son introducidas por conjunciones explicativas como «o sea», «es decir»; «puedes acomodarte, es decir sentarte»; «un principio, o sea una regla».

11.10. Las expresiones tautológicas, como por ejemplo «los volátiles vuelan» ${ }^{51}$, «pensar un pensamiento», «idear una idea», «agguzzare l'ingegno», etcétera.

11.11. Las expresiones como «nunca jamás» o «è buona norma e regola», en las que si bien la redundancia asume también la forma de una tautología, a diferencia del caso anterior, desempeña a una particular función expresiva.

De los estudios de lingüística sobre las redundancias se pueden extraer algunas lecciones útiles para examinar la redundancia entre normas.

En primer lugar, en la medida en que el derecho - escrito y oral (como por ejemplo los debates en los procesos y en las discusiones orales de las causas) — hace uso de

47 Cfr. ForTIS, 2005: 64-65.

48 Cfr. Romagnino, 2009-2010: 72.

49 Cfr. Guerrero Salazar, 2000: 423-430.

50 C $r$ r. Caterina, Lantella, 2011: 479.

$51 C f r$. Caterina y Lantella, 2011: 481. 
una lengua natural (normalmente aquella/as nacional/es oficiales), las formulaciones de los textos jurídicos, y las normas que de éstos se extraen a través de la interpretación, presentan las redundancias lingüísticas que he apenas mencionado, comenzando por aquellas estructurales propias de la sintaxis y de la morfología del lenguaje. Bajo este aspecto, sería interesante analizar, pero no es ésta la sede para hacerlo, si los lenguajes jurídicos siguen, a este nivel, reglas iguales o diferentes, respecto de las reglas de los lenguajes ordinarios, es decir, analizar si el lenguaje jurídico presenta fenómenos de redundancia morfo-sintáctica propios y adicionales a los del lenguaje natural.

En segundo lugar, la redundancia puede concernir los signos lingüísticos (frases, sintagmas, términos, etc.), o los significados vehiculizados por los signos (los conceptos y sus elementos semánticos). En el derecho es necesario, por lo tanto, distinguir entre la redundancia de las formulaciones jurídicas y la redundancia de las normas. Y, como se ha visto en los ejemplos, de la repetición de los signos no se sigue necesariamente la redundancia de significados (por ejemplo «poco a poco» significa «gradualmente», no repetidamente o dos veces poco, porque «poco» significa otra cosa), ni viceversa (así por ejemplo «contrato de donación» es una expresión conceptualmente redundante en italiano, y en el derecho italiano, porque la donación es un contrato).

En tercer lugar, las redundancias lingüísticas tienen fundamento en la estructura del lenguaje, en las posibilidades de uso y combinaciones de sus signos y lexemas, considerando por lo tanto los significados de las unidades lingüísticas. Pero algunas redundancias son «obligatorias» y otras «facultativas».

Redundancias «obligatorias» son aquellas que, bajo el aspecto estructural, son propias de la sintaxis y de la morfología del lenguaje y, bajo el aspecto funcional, pueden ser consideradas parte de la macro-pragmática de los lenguajes naturales (desde este punto de vista, las redundancias son consideradas un factor de economía, previsibilidad, estabilidad del sistema lingüístico, etc.).

Una redundancia es en cambio «facultativa» cuando, aún teniendo origen en la morfología, en la sintaxis y en el léxico de un determinado idioma, depende de las elecciones lingüístico-discursivas de los usuarios que se sirven de la flexibilidad interna del sistema lingüístico. Este segundo género de redundancias (cfr. punto 11 de la lista precedente) puede apreciarse y se extiende sobre el plano micro-pragmático, considerando las concretas instancias y proferencias en su contexto de uso, en relación con las diferentes funciones del lenguaje, con el objetivo del discurso y las competencias lingüísticas de los usuarios. Esto vale también para los derechos vigentes, caracterizados por una multiplicidad de formas de redundancia, algunas de las cuales propias del lenguaje jurídico y del lenguaje natural en el que se produce el discurso jurídico, y otras fruto de las elecciones discursivas de los participantes de la practica jurídica.

La distinción entre redundancia «obligatoria» y «facultativa» es crucial no sólo sobre el plano descriptivo, sino también respecto de la política del derecho. Esta distinción constituye la base para preguntarse cuáles redundancias no son evitables ni eliminables, dado el uso de una determinada lengua y dadas las características del lenguaje jurídico; y cuáles redundancias, en cambio, siendo fruto de las elecciones lingüísticas del legislador, de los jueces, de los funcionarios, etc., son una variable con- 
tingente de las prácticas jurídicas y, como tales, de iure condendo, son modificables y eventualmente eliminables o sustituibles.

En cuarto lugar, volviendo al fenómeno de las normas especiales y generales, en los derechos vigentes, la coexistencia de normas especiales y generales (derogatorias o no, compatibles o incompatibles) es un factor de redundancia significativo, si bien no es ciertamente el único, tal como muestra la lista anterior. La redundancia entre normas especiales y generales, mientras que sobre el plano lógico es una consecuencia necesaria de la especialidad, sobre el plano lingüístico representa un fenómeno no unitario que puede tener orígenes y características diferentes, tal como sucede en lingüística, y responder a diferentes exigencias macro- y micro-pragmáticas. Las redundancias entre normas (especiales y generales) constituyen un fenómeno más extendido que el de las antinomias jurídicas («parciales-totales»), tan es así que — como se ha dicho-, también las normas (especiales y generales) incompatibles dan lugar a redundancias, teniendo un ámbito común de calificación.

\section{LAS REDUNDANCIAS ENTRE NORMAS (ESPECIALES Y GENERALES)}

Intentemos aplicar en ámbito jurídico el análisis precedente de las redundancias lingüísticas, considerando algunos ejemplos.

\subsection{Disposiciones que expresan varias normas que están, entre sí, en relación de especialidad}

U.S. Code: Title 18, Part I, Chapter 44, \$ 924 (c) (1)(A): «... any person who, during and in relation to any crime of violence or drug trafficking crime (including a crime of violence or drug trafficking crime that provides for an enbanced punishment if committed by the use of a deadly or dangerous weapon or device) for which the person may be prosecuted in a court of the United States, uses or carries a firearm, or who, in furtherance of any such crime, possesses a firearm, shall, in addition to the punishment provided for such crime of violence or drug trafficking crime - (i) be sentenced to a term of imprisonment of not less than 5 years; (ii) if the firearm is brandished, be sentenced to a term of imprisonment of not less than 7 years; and (iii) if the firearm is discharged, be sentenced to a term of imprisonment of not less than 10 years».

Entre paréntesis están indicados los elementos que son redundantes a nivel semántico ${ }^{52}$. En efecto, el paréntesis explicita una sub-clase de crímenes (violencia y tráfico de droga cometidos con uso de armas u otros medios mortales o peligrosos) ya incluidos, por definición, en las figuras criminales generales de la violencia y del tráfico de estupefacientes. Los verbos «use», «carry», «posses» («a firearm») tienen un área común de significado, puesto que expresan conceptos parcialmente, si no totalmente, equivalentes. Los elementos citados representan, el primero, el presupuesto (general

52 Cfr. MORRA, 2011. 
y especial) de la conducta, el segundo, las tres conductas castigadas. Tenemos, por lo tanto, una disposición que expresa varias normas en relación de especialidad. La elección de identificar clases y subclases de hechos, mediante categorías generales, especificaciones explícitas y enumeración de elementos redundantes, responde — por lo menos en las intenciones de los legisladores penales-- por un lado, al objetivo de lograr una mayor precisión en las formulaciones, y por el otro, al objetivo de reducir los márgenes de discrecionalidad interpretativa de los tribunales ${ }^{53}$.

\subsection{Normas definitorias generales y normas especiales de conducta y sancionadoras}

Art. 2, L 21 noviembre del 2000, n. 353, Ley marco en materia de incendios forestales «1. Por incendio forestal se entiende un fuego susceptible de expandirse hacia áreas boscosas, con arbustos o arboladas, comprendidas eventuales estructuras e infraestructuras realizadas por el hombre dentro de las áreas mencionadas, o bien hacia terrenos cultivados o incultivados y pastizales limitrofes a dichas áreas».

Art. 10 1. cit. «Las zonas boscosas y los pastizales cuya vegetación haya sido afectada por el fuego no pueden tener un uso diferente del que tenían al momento del incendio, por lo menos por 15 años. Está, de todos modos, permitida la construcción de las obras públicas que sean necesarias para la salvaguardia de la incolumidad pública y del ambiente. En todos los actos de compraventa de áreas e inmuebles situados en las zonas enumeradas, estipulados dentro de quince años de los eventos previstos en el presente artículo, debe estar expresamente mencionado el vínculo especificado en el primer párrafo, bajo pena de nulidad del acto. En los pueblos desprovistas de un régimen regulatorio está prohibida por diez años toda edificación sobre áreas boscosas afectadas por el fuego. Está prohibido además, por diez años, sobre las superficies mencionadas, la actividad de reforestación y de ingeniería ambiental financiadas con recursos públicos, salvo específica autorización concedida por el Ministro del ambiente, en el caso de áreas estatales naturales protegidas, o por la región competente, en los demás casos, siempre que se haya comprobado y documentado una situación de ruina hidrogeológica o cuando sea urgente intervenir para tutelar los valores ambientales y paisajísticos. Están igualmente prohibidas por diez años, en la superficie de las zonas boscosas afectadas por el fuego, la pastura y la caza».

En este caso tenemos una norma definitoria general con algunas especificaciones, redundantes bajo el aspecto lingüístico (semántico), pero que, sobre el plano pragmático, tiene la función de evitar dudas interpretativas. Sin embargo, se trata de un caso de mala legislación, puesto que se delimita el objeto regulado (las situaciones de incendio forestal) a través de la norma definitoria general («Por incendio forestal se debe entender... ») pero luego esa norma es ignorada por las normas que establecen las conductas,

53 Este modo de formular las normas penales, típico del common law inglés, no es extraño a la cultura jurídica europea e incluso se está extendiendo cada vez más. Un ejemplo claro es, de todos modos, el Theft Act 1968 Ch. 60 Definition of «theft», en donde a la Basic definition of theft: «A person is guilty of theft if he dishonestly appropriates property belonging to another with the intention of permanently depriving the other of $i t »$, le sigue la definición de cada uno de sus elementos: «Dishonestly», «Appropriates», «Property», «Belonging to another», «With the intention of permanently depriving the other of it». 
las sanciones, etc. La consecuencia es que la jurisprudencia termina desconociendo la especificación presente en la norma definitoria general. Así, por ejemplo, la jurisprudencia excluye poder aplicar la norma del art. 10 al incendio de un área cultivada con olivos, ya que para catastro resulta clasificada como área de cultivo agrario. Para la jurisprudencia (cfr. T.a.r. Lazio, sez. II, 17-11-2009, n. 11242), la segunda disposición expresa una norma especial porque limita «la aplicación de las prohibiciones, prescripciones y sanciones a «zonas boscosas y pastizales cuya superficie» haya sido afectada por el fuego», y no a las «zonas arboladas»y, por lo tanto, se trata de «un conjunto de áreas naturales y vegetales más delimitado respecto» a aquel objeto de la norma definitoria. Una vez constatado que «en la definición de «bosque» el legislador, tanto nacional como regional, ha previsto una equiparación del mismo a la floresta y a la selva [...] y ha identificado algunos casos asimilados a bosque [...], y además ha diferenciado la vegetación forestal de aquella arbustiva [...]», se concluye que ninguna norma nacional o regional se refiere precisamente a «los cultivos del olivo y mucho menos califica estos últimos como vegetación arbolada perteneciente al patrimonio forestal, selvático, naturalista» protegido por la L. n. 353 del 2000. Un olivar, para los jueces, es un «cultivo que no entra entre los que quedan comprendidos por el concepto de "bosque"», porque «como los frutales, los olivares están desprovistos de características forestales, que en el uso corriente se identifican con el ser un bosque no cultivado, denso, intrincado, espeso y constituido también por árboles de especies diferentes».

\subsection{Especificaciones redundantes que expresan anti-reglas}

Art 1.269 Cod. Civ. it.: «El tercero autorizado para realizar el pago no está obligado a aceptar el encargo, aun cuando sea deudor del delegante».

La disposición en cuestión introduce una especificación redundante sobre el plano semántico, que tiene la función de excluir que el intérprete obtenga la siguiente antiregla: el deudor del delegante está obligado a aceptar el encargo. Considerando esta anti-regla probable, el legislador ha precisado, de manera preventiva, que tampoco el deudor del delegante está obligado a aceptar el encargo ${ }^{54}$.

\subsection{Normas especiales y generales redundantes y discontinuidad histórica de la regulación}

Art 1.178 CC it.: «Cuando la obligación tiene por objeto la prestación de cosas determinadas solamente en el género, el deudor debe dar cosas de calidad no inferior a la media».

Art. 664 CC it.: «En el legado de cosa determinada solamente por el género, la elección, cuando el testador no la haya confiado al legatario o a un tercero, le compete al heredero. Éste está obligado a dar cosas de calidad no inferior a la media [...]».

Art. 1.286, inciso 1, CC it.: «La elección [i.e. en las obligaciones alternativas] le compete al deudor, si no ha sido atribuida al acreedor o a un tercero».

${ }^{54}$ Cfr. Caterina y Lantella, 2011: 485-487. 
Art. 665 CC it.: «En el legado alternativo la elección le compete al heredero, a menos que el testador se lo haya dejado al legatario o a un tercero».

Las disposiciones sobre la elección en el legado alternativo (supra art. 664 y 665 CC it.) expresan normas especiales, compatibles respecto de las normas generales referidas a las obligaciones alternativas (supra arts. 1.178 y 1.286 CC it.). El legislador repite casi en su totalidad las mismas palabras; las únicas variaciones son «a menos que»/«si no», que tienen una idéntica función gramatical; y «legatario» en lugar de «acreedor» $\mathrm{y}$ «heredero» en lugar de «deudor», pero entre legatario y heredero hay una relación obligatoria de crédito-debito. Aquí, la redundancia tiene quizás razones históricas, ya que en virtud de la parcial discontinuidad del actual Código respecto al CC de 1865, la redundancia parece tener por función (desde la óptica del legislador de 1942), más que evitar una duda interpretativa o excluir una probable anti-regla, facilitar la reconstrucción de la disciplina del legado (en parte nueva en 1942), sin que sea necesario consultar otras partes del Código.

\subsection{Normas especiales y generales limitativas y objetivos de política del derecho}

Art. 30, inciso 1, L. 183/2010, Cláusulas generales y certificación del contrato de trabajo: «1. En todos los casos en los que las disposiciones de ley, en las materias mencionadas en el artículo 409 del código de procedimiento civil y en el artículo 63, inciso 1, del decreto legislativo del 30 de marzo de 2001, n. 165, contengan cláusulas generales, incluidas las normas referidas al establecimiento de una relación de trabajo, al ejercicio de los poderes patronales, a la transferencia de empresa y al receso, el control judicial se limita exclusivamente, en conformidad con los principios generales del ordenamiento, a la comprobación del presupuesto de legitimidad y no puede extenderse a un control sustantivo de las valoraciones técnicas, organizativas y productivas que competen al dador de trabajo o al comitente.

La disposición citada expresa una norma especial limitativa y para reforzar este objetivo es redundante bajo varios aspectos. Primero, «las normas en materia de establecimiento de una relación de trabajo, de ejercicio de los poderes patronales, de transferencia de empresa y de receso» están ciertamente «incluidas» en la materia de trabajo en relación de dependencia privado, ex art. 409 Cod. Proc. Civ. it., y en la materia de empleo público, ex art. 63, d. lgs. 165/2002. Además, un límite, por definición, fija una exclusión («limitado exclusivamente»). Luego, dado la oposición «legitimidad»/«sustantivo», tertium non datur, por lo que el agregado «no puede extenderse...» es tautológica. Igualmente, los adjetivos «técnicas, organizativas y productivas» comparten un área de significado común y constituyen una tríada, son tres elementos constitutivos de un todo. Bien se podría haber escrito: toda valoración que compete al dador de trabajo ${ }^{55}$, donde el problema es dado, en cambio, qué compete y qué no compete al dador de trabajo.

55 Omito la referencia al «mandante», que es también redundante, porque en este caso en vez de ser un agregado útil crea confusión; en materia de trabajo en relación de dependencia privado y de empleo público no hay un mandante, el cual — según al Código civil— es por el contrario una de las partes de un contrato de obra sin vinculo de subordinación. 
Otro elemento de redundancia es el requisito de la «conformidad con los principios generales del ordenamiento». La redundancia aquí se aprecia haciendo una prueba de sustitución. Es evidentemente un sin sentido disponer que el control judicial debe ser cumplido «en no conformidad», o sea, en contraste con los principios generales del ordenamiento.

Las formas de redundancia apenas vistas son difundidísimas en la historia del derecho y tienen que ver precisamente con normas o principios generales que también tienen la misma función de limitar los poderes judiciales. Es emblemático en tal sentido el art. VIII de la Déclaration des droits de l'homme et du citoyen del 1789: «La Loi ne doit établir que des peines strictement et évidemment nécessaires, et nul ne peut être puni qu'en vertu d'une Loi établie et promulguée antérieurement au délit, et légalement appliquée». El requisito de la legalidad, expresado por el adverbio «legalmente», es redundante, tanto que, como hemos visto, si se intenta sustituirlo con el opuesto «ilegalmente», se genera un sin sentido. Además, es una contradicción en los términos hablar de necesidad no estricta o laxa («strictement... nécessaires»); algo que es no estrictamente necesario, simplemente es no necesario; y lo mismo vale para «évidemment nécessaires». La expresión «établie et promulguée» es una hendíadis, porque la promulgación de una ley incluye que la ley haya sido aprobada. La función declamatoria de la norma en cuestión justifica —o por lo menos explica históricamente— las redundancias apenas vistas.

\subsection{Especialidad/identidad entre normas y redundancia como defecto de redacción}

Art. 24 TFUE (ex art. 11 TUE). «(..) La política exterior y de seguridad común se regirá por reglas y procedimientos específicos. La definirá y aplicarán el Consejo Europeo y el Consejo, que deberán pronunciarse por unanimidad salvo cuando los Tratados dispongan otra cosa. Queda excluida la adopción de actos legislativos».

Art. 31 TFUE (ex art. 23 TUE). «El Consejo Europeo y el Consejo adoptarán por unanimidad las decisiones de que trata el presente capítulo [i.e. disposiciones específicas sobre política exterior y de seguridad común], salvo en los casos en que el presente capítulo disponga otra cosa. Se excluye la adopción de actos legislativos».

Estas formulaciones expresan normas completamente redundantes, tan es así que se puede discutir si estamos frente a dos normas idénticas o si una es más general que la otra. Se trata sólo de dos ejemplos de la técnica adoptada por el legislador europeo para la redacción de los Tratados UE y FUE. En este caso, la redundancia tiene una naturaleza tal que puede ciertamente ser considerada un defecto que en verdad no se compensa con otras funciones discursivas relevantes (por ejemplo, expresivas respecto de los destinatarios, o reforzadoras la eficacia, o declamatorias, etc.). La norma que se obtiene a partir de estas dos disposiciones podría haber sido formulada así: «La política exterior y de seguridad común será definida y aplicada mediante decisiones del Consejo Europeo y del Consejo, que deberán pronunciarse por unanimidad, excepto que los tratados dispongan otra cosa. Queda excluida la adopción de actos legislativos». 


\subsection{Normas generales, iteraciones de símbolos y normas especiales «locales»}

Art. 51. Tutela de la salud de los no fumadores, L. del 16 de enero de 2003, n. 3 : «1. Está prohibido fumar en los locales cerrados, con la excepción de: a) locales privados no abiertos a usuarios o al público; $b$ ) locales reservados a los fumadores y señalados como tales».

Esta disposición expresa una norma general prohibitiva. Como es notorio, en los locales cerrados, no abiertos al público ni reservados a los fumadores, existen señales que indican la prohibición de fumar. También en este caso tenemos una redundancia (si hacemos caso a los símbolos y señales). Pero no consideramos este caso como una redundancia entre normas, porque interpretamos los símbolos individuales de prohibición, no como normas específicas relativas (sobre bases pragmáticas) al lugar en cuestión, sino como meras iteraciones señaléticas, sin fuerza normativa propia. Lo mismo sucede entre, por un lado, la obligación de viajar con pasaje (convalidado) en los medios de transporte públicos y, por otro lado, los avisos al respecto publicados en dichos medios. Me limito a mencionar esta hipótesis, puesto que no es para nada obvio que semejantes señales no deban o puedan ser interpretadas como normas que poseen un ámbito de aplicación local. Un contra-ejemplo lo constituyen las señales viales, que todos nosotros interpretamos como prohibición (de circulación en un determinado sentido, a una determinada velocidad, por un determinado segmento de calle, etc.), permisos de acceso, obligaciones de detención, deberes de movimiento (señal verde), etcétera ${ }^{56}$.

\subsection{Normas especiales expresas redundantes respecto a normas o principios generales tácitos sobre ordenados}

Art. 2. Convenciones internacionales de la L. 218/1995 de Reforma del sistema italiano de derecho internacional privado; «1. Las disposiciones de la presente ley no afectan la aplicación de las convenciones internacionales en vigor para Italia».

Esta disposición y la norma que se obtiene son redundantes bajo dos aspectos. Primero, que una norma de ley ordinaria (como la L. 218/1995) no pueda afectar normas de convenciones internacionales (incluso si son de derecho internacional privado y procesal) deriva del principio pacta sunt servanda. Principio vigente en el derecho italiano (sin que sea relevante la tesis acerca del derecho internacional que se asuma) en virtud de una norma expresa en la Constitución (cfr. art. 10 de la Constitución: «El ordenamiento jurídico italiano se adecua a las normas del derecho internacional generalmente reconocidas»). Segundo, es redundante el agregado «en vigor para Italia», porque si una convención no está en vigor, no existe la obligación de observarla y sus normas no pueden ser aplicadas, ni prevalecer. La doctrina, aún considerando el agregado superfluo, lo interpreta como un llamado a prestar atención a eventuales reservas en los tratados.

56 Cfr. LAZZARO, 1985: 43 y ss., considera que la mayor parte de las redundancias en el derecho son de tipo parcial, como en el ejemplo «de la señal mas genérica «prohibido adelantarse por dos kilómetros». Y luego la simple «prohibición de adelantarse» repetida a lo largo de esos dos kilómetros de ruta, generalmente en los puntos mas peligrosos». 


\subsection{Normas generales (que confieren poderes) y normas especiales de actuación redundantes}

Ley Orgánica 6/2001, del 21 de diciembre, de Universidades, Título Preliminar, De las funciones y autonomía de las Universidades, Art. 1. Funciones de la Universidad. «2. Son funciones de la Universidad, al servicio de la sociedad: a) La creación, el desarrollo, la transmisión y la crítica de la ciencia, de la técnica y de la cultura. [...] c) La difusión, la valorización y la transferencia del conocimiento al servicio de la cultura, de la calidad de la vida, y del desarrollo económico».

Art. 2. Estatutos de la Universidad Carlos III de Madrid ${ }^{57}$ : «En el cumplimiento de las funciones que le corresponden según las Leyes, la Universidad: [...] b) Velará por el adecuado desarrollo de la docencia para la transmisión y crítica de la ciencia, de la técnica y de la cultura. [...] f) Procurará la mayor proyección social de sus actividades, mediante el establecimiento de cauces de colaboración y asistencia a la sociedad, con el fin de apoyar el progreso social, económico y cultural».

Art. 152. Estatutos de la Universidad Carlos III de Madrid: «La Universidad contribuirá al desarrollo cultural, social y económico de la sociedad y procurará la mayor proyección de sus actividades. Para ello, a iniciativa propia o en colaboración con entidades públicas o privadas, promoverá la difusión de la ciencia, la cultura y el arte por los siguientes medios: a) Los acuerdos o convenios de carácter general. b) Los trabajos de asistencia científica, técnica o artística. c) La extensión universitaria».

Este ejemplo ilustra un caso recurrente de normas especiales que no derogan, sino que se integran con las normas generales. El caso de las normas especiales de actuación. Interpretando las disposiciones citadas se obtienen normas generales (de rango jerárquico superior, en el caso bajo análisis, preceptos con fuerza de «ley orgánica») y especiales de actuación (de rango jerárquico inferior), ampliamente redundantes. No se trata de un caso aislado. En los derechos vigentes muchísimas normas especiales de actuación prescriben lo mismo, de manera diferente, en lugar de limitarse a especificar lo que prescriben las normas generales. La integración resulta evidente especialmente si, respecto de las normas generales que han de ser actuadas, las normas especiales de actuación tienen un rango jerárquico inferior en el plano formal, como en el ejemplo. La diferencia de rango jerárquico es sin embargo sólo un elemento accidental. Puesto que, el hecho que las normas especiales de actuación por lo general no deroguen las normas generales depende del contenido de la norma general. En particular, no existe derogación cuando la norma general es una norma que confiere poderes (normativos). En efecto, en la medida en que la norma general es una norma que confiere un poder normativo, las normas especiales de actuación son dictadas en ejercicio de ese poder y, en consecuencia, por definición no derogan, sino que, precisamente, actúan, integran, especifican la norma general de delegación ${ }^{58}$.

57 Texto unificado, Decreto 95/2009, del 12 de noviembre, del Consejo de Gobierno, por el que se aprueba la modificación de los estatutos de la Universidad Carlos III de Madrid, en BOCM, núm. 288, de 4 de diciembre de 2009: 66-77, en bttp://www.uc3m.es.

58 Piénsese por ejemplo, en las normas del Entendimiento entre el Ministro de bienes y actividades culturales y el Presidente de la Conferencia episcopal italiana, firmado el 26 de enero 2005, relativa a la tutela de los bie- 


\section{OBSERVACIONES FINALES}

El estudio casuístico precedente constituye sólo una muestra parcial. Ilustra sólo algunos casos bastante comunes de normas especiales y generales compatibles, derogatorias y no derogatorias.

A partir de los ejemplos es posible advertir que, desde el punto de vista lingüístico, el fenómeno de la redundancia entre normas es extremadamente variado y que el nivel de análisis que permite discernir los diferentes casos es nivel semántico-pragmático. La redundancia, aun cuando nazca entre los pliegues del lenguaje, se identifica y explica sobre la base de las funciones lingüísticas y de los objetivos del discurso.

Las redundancias pueden servir así para evitar dudas interpretativas, para excluir determinadas interpretaciones probables, para explicitar objetivos de política del derecho, para facilitar el hallazgo del material normativo, para demostrar continuidad en la actuación de las normas más generales. Pueden ser el indicador de normas implícitas. Son necesarias cuando las normas tienen una esfera de aplicación espacial local. Pueden ser síntomas de defectos de redacción de los textos jurídicos o, por el contrario, pueden cumplir una precisa función expresiva, de énfasis o, incluso declamatoria. A esta lista se pueden agregar todavía dos posibilidades más: el caso de las normas especiales redundantes que tienen la función de expresar la ratio o el fundamento que justifica un conjunto de otras normas más específicas ${ }^{59}$; y el caso de las redundancias en la regulación de especies que son nuevas para un determinado derecho (por ejemplo «el pacto de familia») y que sirven para asociar el instituto apenas legislado con un género que es ya tradicional en ese derecho (en el ejemplo, el contrato) ${ }^{60}$.

(Traducción de Magdalena Ana Rosso)

nes culturales de interés religioso pertenecientes a entes e instituciones eclesiásticas, al que se ha dado actuación mediante el D.P.R. de 4 de febrero de 2005, n. 78. Tales normas tienen carácter aplicativo, de actuación e integrativo de la norma general del el art. 12 del Acuerdo, con protocolo adicional, firmado en Roma el 18 de febrero de 1984, y que, a su vez, introduce modificaciones al Concordato lateranense del 11 de febrero de 1929, entre la Republica italiana y la Santa Sede, ratificado con L. 25-3-1985 n. 121 según el cual «La Santa Sede y la República Italiana, en sus respectivos ámbitos, colaboran para la tutela del patrimonio histórico y artístico. Con el fin de armonizar la aplicación de la ley italiana a las exigencias de carácter religioso, los órganos competentes de las dos Partes concordaran oportunas disposiciones para la salvaguardia, la valorización y el usufructo de los bienes culturales de interés religioso pertenecientes a entes e instituciones eclesiásticas». Cfr. LUGLI, 2012: 347-355.

59 Cfr. por ejemplo art. 121 Cod. Proc. Civ. it. «Libertad de las formas» que dispone que «Los actos del proceso, para los cuales la ley no dispone formas específicas, pueden ser realizados en la forma que sea más idónea para alcanzar su objetivo». La doctrina italiana subraya que el artículo expresa una norma especial, manifestación del principio general de la libertad de las formas en materia de actos procesales y observa que, si bien es difícil imaginar actos del proceso para los cuales la ley no predetermine formas, y «por lo tanto la norma en examen podría parecer superflua [...] según su alcance literal», ésta no es para nada superflua según su alcance sistemático, en virtud de su típica función de clausura del sistema [...] la norma bajo examen desempeña la importante función de señalar al intérprete de todas las normas que se refieren a las formas de los actos procesales, que a ese mismo criterio — - según el cual las formas deben ser las más idóneas para alcanzar el objetivo- se ha inspirado el legislador cuando no ha omitido disciplinar las formas de los actos, sino que los ha efectivamente disciplinado», MANDRIOLI y CARRATTA, 2012: 259.

${ }^{60}$ Así, el art. 768-septies CC it. según el cual «El contrato puede ser resuelto o modificado por las mismas personas que han celebrado el pacto de familia [...] mediante un contrato diferente, con las mismas características y los mismos presupuestos» previstos para el pacto de familia mismo, enuncia una norma redundante respecto del art. 1.372 CC it. según el cual «El contrato [...] puede ser disuelto por consenso mutuo». El art. 768-quinquies, $1 .^{\circ}$ inc., CC. it., según el cual «El pacto [de familia] puede ser impugnado por los partici- 


\section{BIBLIOGRAFÍA}

BAREL, B., y ARMelLini, S., 2011: Manuale breve di diritto internazionale privato, Milano, Giuffrè.

Canon-Roger, C. F., 2006: Littérature et linguistique 1, Diversité des langues (XI), 1, en bttp:// www.revue-texto.net/Reperes/Themes/Canon-Roger/Canon-Roger1.btml.

CARston, R., 2008: Thoughts and Utterances: The Pragmatics of Explicit Communication, e-book, Wiley.

Casuscelli, G., 2012: «Elementi introduttivi», en G. Casuscelli (a cura de), Nozioni di diritto ecclesiastico, Torino, Giappichelli, 4. ${ }^{a}$ ed.

Caterina, R., y Lantella, L., 2011: «Il diritto che non c'è», Riv. dir. civ. (57), 4: 477-489.

CHIARI I., 2002: Ridondanza e linguaggio. Un principio costitutivo delle lingue, Roma, Carocci.

De Martini, A. L., 2006: «Introduzione», a Frate Antonio Maria de Esterzili, Libro de commedias, Cagliari, CUEC.

Droste, F. G., 1976: «Semantics as a Dynamic Device: Redundancy Rulesin the Lexicon», Linguistics, 182: 5-33.

EL KASSAS, D., 2011: «Representation of Zero and Dummy Subject Pronouns within multistrata dependency framework», paper presentato all' International Conference on Dependency Linguistics, Barcelona, September 5 luglio 2011, en bttp://depling.org/.

FERRER, J., y RodrígueZ, J., 2011: Jerarquías normativas y dinámica de los sistemas jurídicos, Madrid, Marcial Pons.

FIORENTINO, S., 2012: «La libertà di religione», en G. CASUSCELLI (a cura de), Nozioni di diritto ecclesiastico, Torino, Giappichelli, 4. ${ }^{\text {a }}$ ed.

FORTIS, D., 2005: «Il linguaggio amministrativo italiano», Revista de Llengua i Dret (43): 47-116.

GARDELLA, A., 2007: Le garanzie finanziarie nel diritto internazionale privato, Milano, Giuffrè.

Guerrero SAlazAr, S., 2000: «Las redundancias en español: un medio para pulir la lengua en los niveles de perfeccionamiento», ¿Qué español enseñar?: norma y variación lingüísticas en la enseñanza del español a extranjeros: actas del XI Congreso Internacional ASELE, Zaragoza 13-16 de septiembre de 2000: 423-430.

HÉBERT, L., 2012: «Polysémiotique (Produit -) ad vocem», Dictionnaire de sémiotique générale, avec coll. de G. DumOnT MORIN, en http://www.signosemio.com/documents/dictionnairesemiotique-generale.pdf.

Heilmann, L., 2002: «Introduzione», a R. JakOBSON, Saggi di linguistica generale, Milano, Feltrinelli.

Horning, A. S., 1982: «Redundancy and Readability», Reading Horizons (22), 4: 275-281.

- 1991: «Readable Writing: The Role of Cohesion and Redundancy», Journal of Advanced Composition (11) 1: 135-145.

JakOBSOn, R., 2002: Saggi di linguistica generale, Milano, Feltrinelli.

Langehdoen, D. T., 1967: «The Nature of Syntactic Redundancy», Computer and Information Sciences, II, New York, Academic Press Inc., 303-314.

LAZZARO, G., 1985: Entropia della legge, Torino, Giappichelli.

Lugli, M., 2012: «I beni culturali», en G. CASUSCELli (a cura de), Nozioni di diritto ecclesiastico, Torino, Giappichelli, 4. ${ }^{\mathrm{a}}$ ed.

pantes conforme a los artículos 1.427 y siguientes», reenvía de manera redundante a la disciplina general de la anulación del contrato: así por ejemplo TORRENTE y SCHLESINGER, 2012: 1301. 
Malatesta, A., 2011: «Titoli di credito (voce)», en R. BARATTA (a cura de), Dizionario di diritto internazionale privato, Milano, Giuffrè, 485-492.

MANDrIOLI, C., y CARRATTA, A., 2012: Corso di diritto processuale civile. I ó Nozioni introduttive e disposizioni generali, Torino, Giappichelli, 10. ${ }^{\mathrm{a}} \mathrm{ed}$.

PANeK, G., 2009: «Towards a Norm-Based Approach in Translation of Legal Provisions/Rola normy prawnej w przekładzie przepisów prawnych», Investigationes Linguisticae (17): 75-83.

Pelchat, R., 1983: «La redondance de la langue écrite et ses incidences sur la lecture», Québec français, 52: 78-81.

PotTIER, F., 1974: Linguistique générale. Théorie et description, Paris, Klincksieck.

Pulgram, E. 1983: «The Reduction and Elimination of Redundancy», en F. B. AGARD, G. KeLLEy, A. MAKKaI, y V. BeCKer MAKKaI (eds.), Essays in honor of Charles F. Hockett, Leiden, E. J. Brill: 107-125.

RASTIER, F., 1991: Sémantique et recherches cognitives, Paris, PUF.

Rastier, F.; CAVAZZA, M., y Abeillé, A., 1994: Sémantique pour l'analyse, Paris, Masson.

Romagnino, R., 2009-2010: Ammiano Marcellino, Res gestae XVI, Saggio di commento, Tesi di dottorato in «Storia, Letterature e Culture del Mediterraneo», XXII ciclo, Università degli Studi di Sassari.

ŠABRŠUla, J., 1975: «Redondance et Économie», Acta Universitatis Carolinae, Philologica, Romantica, Pragensia, 9: 101-124.

Sornicola, R., 1995: «La languée et les pronoms sujets», Communication and Cognition: La Deixis temporelle, spatiale et personnelle, 41-70.

- 2006: «Un problema di linguistica generale: la definizione degli espletivi», en R. BOMBI, G. Cifoletti, F. Fusco, L. InNOCEnTE y V. ORIOles (a cura de), Studi linguistici in onore di Roberto Gusmani, Alessandria, Ed. dell'Orso, 1651-1671.

STRAWSON, P. F., 1974: Subject and predicate in logic and grammar, London, Methuen.

Suleiman, S. R., 1980: «Redundancy and the "Readable" Text», Poetics Today, Special Issue: Narratology I: Poetics of Fiction (1) 3: 119-142.

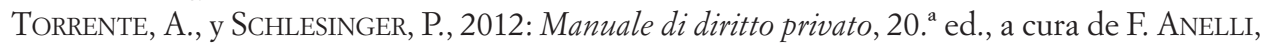
y C. GranelLi, Milano, Giuffrè.

KIELAR, B. Z., 1973: Angielskie ekwiwalenty polskich terminów prawnoustrojowych, Warszawa, PWN.

WierzBiCKA, A., 1993: «La quête des primitifs sémantiques: 1965-1992», Langue Française, 98: 9-23.

WIERZBICKA, A., 2007: «Sens et grammaire universelle: théorie et constats empiriques», in bttp:// linx.revues.org/520.

ZORZETTO, S., 2010: La norma speciale. Una nozione ingannevole, Pisa, ETS. 